\title{
Accelerator plans stalled after US and UK cuts
}

The machine on which the world's particle physicists have staked the future of their discipline hangs in the balance owing to budget cuts.

On 18 December, the US Congress passed a spending bill slashing funding for the International Linear Collider (ILC), a 31-kilometre machine to collide electrons with positrons, by three-quarters to just $\$ 15$ million in 2008 , money that has already been spent. The United States pays for around a third of the collider's roughly \$100-million-120million annual global research and development effort. And a week earlier, the United Kingdom announced that it was withdrawing from the project,

\section{"This makes things} look pretty grim for a real international machine." describing plans for it as "not credible". The decision will help make up an $£ 80$-million (\$160-million) shortfall at the funding body responsible for UK high-energy physics.

The situation is "dire", says Barry Barish at the California Institute of Technology in Pasadena, who heads the global design effort. The linear collider's design was scheduled to be finished in 2010 but will now be delayed until at least 2012. "We have to defer, delay and stretch out," he says.

Burton Richter, a Nobel laureate and former director of the Stanford Linear Accelerator in California, says the project is fragmented politically, with international collaboration at a low: "This now makes things look pretty grim for a real international machine."

The linear collider is the planned successor to the Large Hadron Collider (LHC), a proton accelerator scheduled to begin operation at CERN, the European particle-physics laboratory near Geneva, in the next few months. By smashing beams of electrons and positrons at energies of up to $500 \mathrm{GeV}$, the linear collider will provide a cleaner signal than its LHC counterpart. Barish's team says it will cost around $\$ 7$ billion.

Given that the LHC has not begun work, it might seem surprising that physicists are planning a next-generation machine. But years of design, environmental assessments and lobbying are required to build such a large and expensive device, says Brian Foster, a physicist at the University of Oxford, $\mathrm{UK}$, who is the project's European director. "These things don't just pop out of the air," he says. "A very large amount of preparatory work is required."

The collider's proponents are organized into three regions - Asia, Europe and the

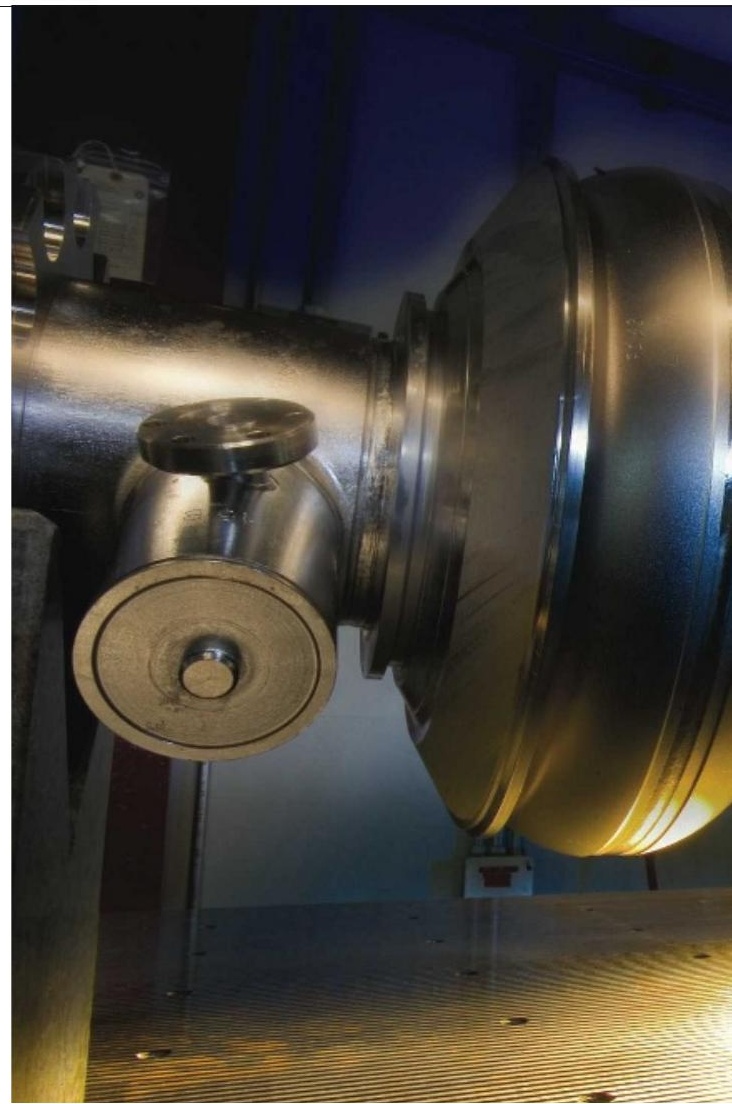

United States. America's main contribution has come from physicists at Fermilab, the high-energy physics laboratory in Batavia, Illinois. But following deep budget cuts, the 170 employees working on the linear collider have been diverted to other projects, says Stephen Holmes, Fermilab's associate director for

\section{India aims for 'quantum jump' in science}

\section{BANGALORE}

India's prime minister

Manmohan Singh has announced unprecedented funding for science education and research, saying it is a top priority for his government. He has announced a range of schemes to attract students and replenish government agencies' shrinking pool of scientific personnel.

“We are planning to fund 30 new Central Universities, five new Indian Institutes of Science Education and Research, eight new Indian Institutes of Technology, and 20 new Indian Institutes of Information Technology," Singh said. In the next five years, he added, India will also

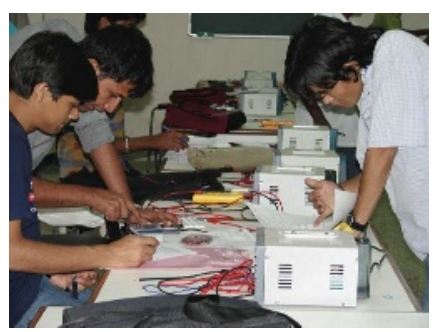

India plans to pay science students.

be launching 1,600 polytechnics, 10,000 vocational schools and 50,000 skill-development centres. One million schoolchildren will receive science innovation scholarships of 5,000 rupees (US\$130) each over the next five years, and 10,000 scholarships of 100,000 rupees per year will go to those enrolling on science degree courses.

Discipline-specific education programmes will be launched in strategic sectors such as nuclear and space sciences "to capture talent at the school leaving stage itself".

Singh unveiled the schemes while opening the week-long 95th Indian science congress, the largest annual meeting of Indian scientists, at Visakhapatnam on 3 January. “We need a quantum jump in science education and research," Singh said. "This agenda can no longer wait. The time has come for action, and
I assure you of my highest personal commitment." Singh said a plan for implementing the proposals will be devised in the next six months. Funding the schemes has required a fivefold increase in the education budget for 2007-12.

The science community has largely welcomed the initiatives, although some express caution. "The money must be spent in a short period of time," says Dipankar Chatterji, a molecular biophysicist at the Indian Institute of Science in Bangalore. "This poses a tremendous challenge to the heads of these institutions."

K. S. Jayaraman 


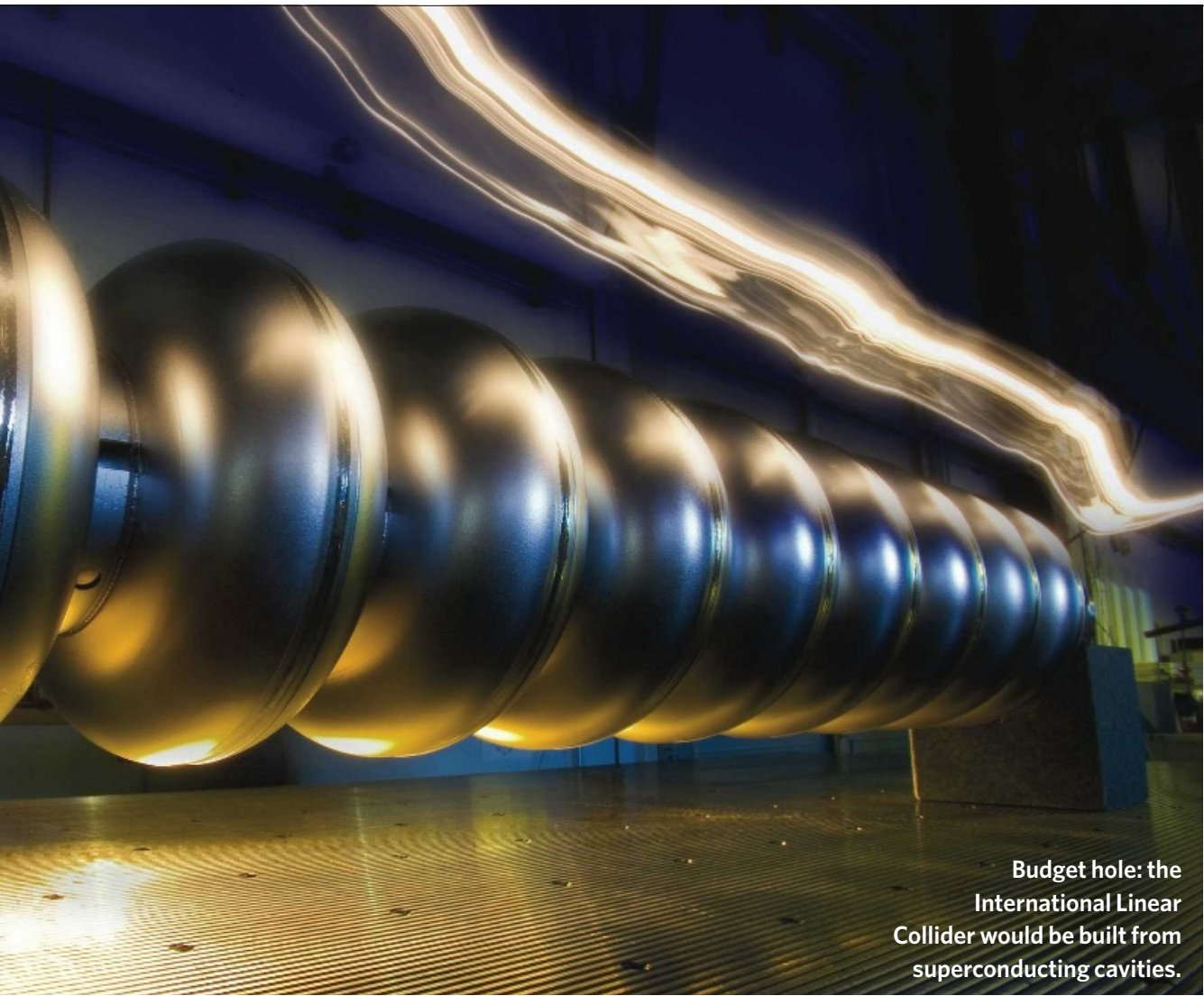

accelerators. Holmes is unsure why Congress slashed the project's funding, but the US government announced a tighter budget for the rest of science too, in part due to the cost of the Iraq war (see Nature 451, 2; 2008).

Physicists in other partner nations do not expect the withdrawals to undermine their own governments' commitments to the collider. In Japan, this year's budget for highenergy physics is already assured - although the government has not yet decided whether it will support the collider - says Mitsuaki Nozaki, a physicist at KEK, the high-energy accelerator research organizarion in Tsukuba and Asian regional director for the collider's design effort. In Germany, work on the superconducting cavities that make up the core of the accelerator will continue, says Rolf-Dieter Heuer, who heads research at the German electron synchrotron, DESY, in Hamburg.

But the prospects for building the machine are murkier now than at any previous point during its planning. Many had hoped that the United States might offer to host the project at Fermilab, but even before the cuts Raymond Orbach, who heads the US Department of Energy's Office of Science, called for the collider to be delayed until results come from the LHC in a few years' time.

"You need the results from the LHC to say if the ILC energies are high enough," Richter says. "Nobody wants to build a machine that isn't going to do anything."

Keith Mason, who heads the UK Science and Technology Facilities Council, has gone further, saying the plan for the accelerator "is not credible financially, politically or in any other way".

Nevertheless, the project's supporters plan to soldier on. Barish says the group will divert research from the United States in an effort to salvage the design phase, and Foster says UK physicists are campaigning to bring the nation back into the project.

Richter says all eyes are on the US budget for 2009 to see if 2008 was a one-year dip. "If something isn't done in the president's budget submission in February or in some kind of supplemental bill, I think the ILC as we now see it is in very big trouble."

Eric Hand and Geoff Brumfiel

See Editorial, page 108.

\section{Could global gardening fix climate change?}

Using biomass fuel on a massive scale in combination with carbon sequestration could return atmospheric carbon dioxide to pre-industrial levels within decades, according to a new analysis.

Peter Read calls his proposal global gardening. To make it work, an area the size of France and Germany would have to be enlisted for growing biomass fuels for a quarter of a century .

"This is the first time it's been demonstrated that you can manage carbon levels in the atmosphere" using biomass, says Read, an economist at Massey University's Centre for Energy Research in Palmerston North, New Zealand. Such a move may be necessary to avoid abrupt climate change, he says.
Referees at the journal Climatic Change rejected Read's paper, but editor Stephen Schneider elected to publish it as an editorial commentary.

"Peter has some very clever and controversial ideas," says Schneider, a climatologist at Stanford University in California. "Climatic Change has long been a venue where clever and controversial ideas can get aired - as long as they are in perspective."

Read envisions an array of plantations supplying commodities such as energy and timber, as well as a livelihood for countless communities. A second phase could combine biomass energy with carbon sequestration, moving society to the point where it sequestered more carbon than it emitted.

Gregg Marland, a climate researcher currently working at the International

\section{"You can manage Institute for Applied Systems} carbon dioxide Analysis in Laxenburg, Austria using biomass." has numerous doubts about the proposal, including crop productivity, implementation and land use. He co-authored a commentary suggesting that it's unclear whether Read's vision is "a dream or a nightmare".

But it's still a useful thought experiment, he says. "I think what Peter has done is paint a picture: if we really get into trouble with carbon dioxide, how can we back off?" Jeff Tollefson 